\title{
Cosmochemistry in China
}

\begin{abstract}
Over the past 30 years Chinese cosmochemists have done much work on cosmochemistry and related disc $i$ plines, especially on the Jilin. Qingzhen and Xinjiang meterrites, on cosmic dusts, tektites and impact glass. boundary impact events and comparative planetology as well as on the origin and evolution of the Earth. In this article, the authors outline the main achievements since 1976 and briefly describe some new views and hypotheses.
\end{abstract}

\section{Introduction}

Cosmochemistry is the study of the chemical constitution and evolution of the universe, especially the solar system. Solat nebulae cot lapsed. collided. and accreted to form planetesimals ranging in diam eter from several to thousands of kilometres. Some of the largest planetesimals accreted to form nine planets: and some of the second largest planetesimals, moving around the planets, hecame satellites while planetesimals which did not grow by accretion comprise the asteroid belt between Mars and Jupiter. Fragments of planetesimals which escape from the orbit of the parent body in the process of impact. become "meteorites' when they intersect the orbit of the Farth, and fall. Because they usually contain materials from the primordial solar nebulae or interstellar nebulac. comets, cosmic dust and meteorites are important sources of information on the origin and evolution of cosmic matter and lile

China has one of the most most systematically documented and richest meteorite records with more than 700 being recorded in the country's history. The earliest record is in a famous ancient Chinese book the Spring and Aatum Chromicle in which is described the meteorites which fell in 645 BC over Shanguiu County. Henan Province. China is also the country in which iron meteorites were first utilised. The iron blade of a bronze weapon, excavated from a Shang Dynasty grave (c. 13th century BC) at Gaocheng County, Hebei Province, was made of iron meteorites.

The famous Jilin meteor shower on March 8.1976 was a fortu nate event for Chinese cosmochemical research. The largest-known meteor shower in the world, it weighed a total of $2600 \mathrm{~kg}$ and scattered debris over an area of $500 \mathrm{~km}^{2}$. The largest fragment $\left(1770 \mathrm{~kg}_{\mathrm{g}}\right)$ penetrated the frozen soil to a depth of six metres, causing mushroom-shaped smoke and dust clouds up to $50 \mathrm{~m}$ high. Soon alterwards, a joint scientific study team led by the Meteorite and Cosmochemistry Division, Institute of Geochemistry, Chinese Academy of Sciences was established to carry out extensive and in-depth studies on the Jilin meteorites, including petrology, mineralogy, chemical composition, chronology, isotopes and evolution history of heat cosmic ray irradiation, impact etc. Meanwhile, there was successful cooperation with many countries including the United States, Germany. Switzerland and Japan, and a series of high-quality articles were published about the event. The Jilin meteorites boosted the development of Chinese cosmochemistry and related subjects, and led to new research into, for example, lunar science, tektites, and the huge impact events of the Cenozoic with their consequent mass extinctions, palaeoclimate cycles, and diaplectic glasses.

\section{Extraterrestrial materials}

\section{Meteorites}

Until now 28 iron meteorites, I patlasite and 60 chondrites have been found in China. All the chondrites. except the Qingzhen enstatite chondrite (EH3) and the Ningqiang carbonaceous chondrite (CV3). are ordinary ones

\section{The Jilin meteorite shower}

On the basis of the mass distribution. fall direction and inclination ete. of its fragments, the parameters of the parent body of the Jilin meteorite were determined and it was shown that, before it fell to Earth, the Jilin metcoritc was moving in a heliocentric ecliptic orbit, similar to that of the Apollo asteroids, and in the direction of revolution of the liarth. It exploded at the altitude of $19 \mathrm{~km}$ above the surface of the Earth. The main characteristics of Jilin meteorite are shown in Table 1 from which it may be concluded that the meteorite has undergone a high degree of thermometamorphism and may be classified as an equilibrated ordinary chondrite. The organic compounds in the meteorite have provided an important basis for exploring the evolution of organic compounds prior to the origin of life.

\section{The Qingahen enstatite chondrite}

The Qingzhen meteorite fell on 13 September, 1976 at Qingzhen County. Guizhou Province, China. The total mass for two fragments recovered was $2.6 \mathrm{~kg}$. No. 1 weighs $600 \mathrm{~g}$. and no. 2 is $2 \mathrm{~kg}$ but it unfortunately fell into water and was weathered badly. The no.l Qingzhen meteorite is one of the most unequilibrated enstatite chondrites (EH3) so far collected in the world and consists of well detined chondrules and chondrule fragments, silicate clasts, isolated grains

Table I Main characteristics of the Jilin meteorite.

\begin{tabular}{|c|c|}
\hline Chemistry & $\begin{array}{llll}\mathrm{Fe} & 28.43 \% & \mathrm{re} / \mathrm{SiO}_{2}: & 0.765 \\
\mathrm{reO} / \mathrm{Fe}: 0.651 & \mathrm{SiO} / \mathrm{MgO} & 1.646\end{array}$ \\
\hline $\begin{array}{l}\text { Primary } \\
\text { mineralogy }\end{array}$ & $\begin{array}{l}\text { chrysolite (with average Fa: } 18.6 \pm 0.1 \text { ) } \\
\text { bronzite (with average Fs: } 14.5 \pm 14.5 \text { ) } \\
\text { iroilite, } \\
\text { kamacite (with average Co: } 4.7 \mathrm{mg} / \mathrm{g} \text { ) }\end{array}$ \\
\hline $\begin{array}{l}\text { Stable } \\
\text { isotopes }\end{array}$ & $\begin{array}{l}\delta^{18} \mathrm{O}: 13.17 \% \\
\delta^{34} \mathrm{~s}: 0.2 \%\end{array}$ \\
\hline $\begin{array}{l}\text { Organic } \\
\text { chemistry }\end{array}$ & $\begin{array}{l}\text { C: } 0.125 \% \text { containing about } 0.0206 \mathrm{mmol} / \mathrm{g} \text { of } \\
\text { amino acids such as lysine, threonine, serine, } \\
\text { proline, glycine, alanine, valine, isoleucine and } \\
\text { leucine, and vanadium porphyrin, nickel por- } \\
\text { phyrin and chlorine compounds in the order of } \\
10)^{\prime} \text {; and also isometric alkane and isoprenoid } \\
\text { such as pristane and phytane }\left(0.37-0.43 \times 10^{-6}\right) \text {. } \\
\text { In addition. alkyl low molecular aromatic hydro- } \\
\text { carbon, alkaline nitrogen compounds, cytosine, } \\
\text { uracil and pyrimidine derivatives are also present }\end{array}$ \\
\hline
\end{tabular}


of enstatite and a variety of metal-sulphide clasts. Like other meteorites, it also has preserved the structure and chemical imprints of the early solar nebular processes. In view of the patterns of trace element distribution and the structure of sulphide phases and the discovery of Ca-bearing sphalerite, we postulate that the sulphides have experienced a complicated heat history and that the Qingzhen meteorite formed under an even more reduced environment with a lower oxygen fugacity than in other enstatite chondrites. Because of its genetic complexity and peculiarities, the Qingzhen meteorite has attracted much attention from Chinese and foreign meteorite researchers. Much work has been done on different aspects of it and more than 40 related aricles have been published so far.

\section{The Xinjiang iron meteorile}

The Xinjiang iron meteorite belongs to the medium octahedrite group of IIIE type and weighs about 28 tons, ranking third in the world behind the Hoba and Cope York. The width of the individual kamacite lamellae is $1.08-1.43 \mathrm{~mm}$, averaging $1.24 \mathrm{~mm}$. Currently, it is on display in the Natural Museum of Urumpi City, Xinjiang Uygur Autonomous Region.

\section{Cosmic dust}

Four flights of high-altitude $(35 \mathrm{~km})$ balloons have been made so far and 276 dust grains greater than $10 \mu \mathrm{m}$ in diameter have been collected. Only four grains are identified as cosmic dust particles. They may be classified into three types:

- fine mineral aggregates with the composition of chondrites:

- mineral fragments of extratertestrial material, and

- ablated meteorites

In China, much work has been done on ablated cosmic particles in Archean and Proterozoic strata and in granites. These particles are composed mainly of $\mathrm{Fe}, \mathrm{Si}$ and trace amount of oxides and show twin layer structures or crust-mantle-core layered structures. Different mineral assemblages and textures exist in the three layers: wustite, magnetite and magnesioferrite in the crust layer; $\alpha$-lerrite and kamacite in the silica-free core; and well-developed gas holes and cavities in the mantle. with melting imprints. The contents of $\mathrm{FeO}, \mathrm{Al}_{2} \mathrm{O}_{3}$ and $\mathrm{CoO}$ of Archean cosmic dust are higher than those of the Proterozoic, but those of $\mathrm{Cr}_{2} \mathrm{O}_{3}, \mathrm{TiO}_{2}$ and $\mathrm{SiO}_{2}$ are lower. Although there is no apparent evidence of geochemical exchange with wallrocks, the composition of cosmic dust grains is not uniform through the grain. This is thought to be the result of auto-differentiation.

\section{Microtektite and diaplectic glasses}

A notable development in Chinese cosmochemistry was the discovery, for the first time in continental sediment-loess, of 16 microtektites and three ablated glassy $\mathrm{Si}-\mathrm{Mg}$ microspherules ranging from $65 \mathrm{~mm}$ to $220 \mathrm{~mm}$ in diameter. These occur in the upper part of loess horizon L8 of the Luochuan loess section, just above the B/M bound ary, and have a sedimentary age of $0.72-0.724 \mathrm{Ma}$. consistent with the host strata of the Australia-Asia microtektites in deep-sea drill cores. The discovery of microtektites in loess moves the boundary of the Australia-Asia microtektite strewnfield $1500 \mathrm{~km}$ northwards. This has important implications in the search for the parent rock and impact crater. From nuclear tests we already know that glassy melt is formed by mixed melting of different petrographic types of target rocks in certain proportion. Based on this, combined with the distribution patterns of the Australia-Asia microtektite groups and the Muong--Nong tektites, we divide Australia-Asia tektites into four sub-groups: Indochina, Indonesia, Philippines and Australia and cal culate the possible petrographic combination of parent rocks.

The debate concerning the origin of tektites has lasted for two centuries but since the Apollo landing of 1969, most scientists have held that tektites are produced by the impact of planetesimals on the Earth. However, a few still consider tektites as the ejecta of lunar volcanoes. Detailed studies of major and trace element composition,
${ }^{40} \mathrm{Ar}-{ }^{39} \mathrm{Ar}$ and fission-tracking age measurements of the Hainan, Guangdong and Guangxi tektites have confirmed that the Chinese tektites belong to the Australia-Asia tektite groups and are of terrestrial impact origin. In addition, the comparative study of chemical constitution, isotope chronology and oxygen isotopes of the globally distributed four major occurrences of tektites, provides new evidence for the origin of terrestrial impact. During recent years a lot of microspherules have been found in strata. Whether these microspherules are of volcanic or impact origin is important to the study of boundary events. We have effectively distinguished impact glass from volcanic glass by means of infrared spectroscopy because these two kinds of glasses differ in the degree of disorder and the environment of formation. Diaplectic glasses are produced by super-velocity impacts and may result from meteorite impacts. shock experiments or nuclear explosions.

\section{Boundary events in the Cenozoic Era}

Since Alvarez et al. found the temporal coincidence of mass extinction with the iridium anomaly in $\mathrm{K} / \mathrm{T}$ boundary clays and suggested that the mass extinction occurring $65 \mathrm{Ma} \mathrm{BP}$ was caused by the impact of planetesimal with a diameter of about $10 \mathrm{~km}$, the KTB event has become an active field of study. The iridium anomaly has also been found in three KTB sections in Gamba, Xizang (Tibet), China, in which the amount of iridium in sediments above or below the Ir-rich layer is less than $0.5 \times 10^{-9}$ and is of normal background level. The values of $8^{13} \mathrm{C}$ and $\delta^{18} \mathrm{O}$ also show fluctuations above the Ir-rich layer. This indicates that the iridium anomalies in the boundary between the Cretaceous and Tertiary are global.

\section{Comparative planetology}

\section{Comparative study of the surface and interior structures of planets}

From a comparative study of their atmospheres, it is verified that the terrestrial planets have atmospheres which retain none of the characteristics of the primary atmosphere formed by condensation of solar nebulae or accretion. Rather, the atmosphere of the Earth has evolved through successive stages from a primary volcanic exhalative atmosphere, though a $\mathrm{CO}_{2}$-rich atmosphere to a $\mathrm{N}_{2}-\mathrm{O}_{2}$ atmosphere. During the evolution of the Earth's hydrosphere, there was an increase in the $\mathrm{pH}$ value of water. Through the comparative study of the craters, rings and linear structure systems on the surface of the Moon, Mercury, Mars and the Earth, we have gained a deeper understanding of the morphogenesis of the terrestrial planets and it is becoming more and more apparent that the mass and the evolution of the interior energy of terrestrial planets controlled the formation and development of the core, mantle and crust structures. The evolution of the planets proceeded in a multi-stage manner.

\section{The significance of impacts in planetary evolution}

Impacts between objects played an important role at almost every stage in the evolution of the solar system, from the formation of metre- or kilometre-sized planetesimals. It is a common and universal phenomenon in the solar system. Many features. such as the high degree of inclination of Uranus, the retrograde spin of Venus, the silicate-poor mantle of Mercury and the formation of the Moon, may all be explained in terms of impact, providing powerful evidence that planetesimals of different sizes existed after the collapse of the solar nebulae and formed the planets. Chinese research has covered the distribution of impact craters on the surface of terrestrial planets and workers have derived the relative ages and relationships of geological bodies involved in cratering events, from the geological record. Search has also been made for craters in China and attention has been given to the impact events and associated mass extinctions at 
the boundaries of the Precambrian/Cambrian, $\mathrm{D}_{1} / \mathrm{D}_{2}, \mathrm{P} / \mathrm{T}, \mathrm{T} / \mathrm{J}$ and $\mathrm{K} / \mathrm{T}$.

\section{Simulation tests}

Chinese geoscientists were the first to use meteorites in shock wave experiments and in high-temperature and high-pressure simulation tests. The simulation experiments have shown that the general partition trend of rare-earth elements in the core, mantle and crust of the Earth was basically established at an early stage; and the ferric inner core, sulphide outer core, Fe-Mg silicate mantle and $\mathrm{Si}$-Al crust of the planets formed sequentially by partial melting and differentiation of the planet interior. When the Earth was in its initial state, sustained outgassing resulting from internal melting produced a volcanic atmosphere, and along with the formation and expansion of a hydrosphere, it evolved to a $\mathrm{CO}_{2}$ atmosphere similar to that of Venus. The modern $\mathrm{N}_{2}-\mathrm{O}_{2}$ atmosphere then gradually developed as carbonates precipitated from seawater and as terrestrial plants flourished. At the same time the $\mathrm{pH}$ value of the hydrosphere dramatically changed: from strongly acidic in the Earth's initial state to weakly alkaline at present.

\section{Primordial inhomegeneity of the Earth}

Of key concern in modern solid geoscience is the origin of inhomogeneity in planet Earth. From 30 years of cosmochemical research Chinese geoscientists have gradually come to the view that the Earth formed by the accretion of planetesimals with different chemical compositions; and the primordial lithosphere of the Earth is composed of a large number of of planetesimals. It is the difference in composition between the planetesimals that resulted in the inhomogeneous spatial distribution of minerals and the later evolution of chemical elements in the crust and mantle.

At an early stage, partial melting and separation of crust from mantle led to the slow formation of elliptical sialic "continental nuclei' surrounded by active magma belts, which we refer to as 'welding belts'. The latter were the sites of Precambrian endogenetic deposits. At around 2-1.8 billion years ago the distribution of heat within the Earth changed, causing a thickening of the lithosphere and the gradual formation of an asthenosphere, thus allowing plate tectonic movements. Some of the above hypotheses have been supported by the preliminary results of work on the Precambrian of eastern Hebei.

\section{References}

Anon. eds., 1979, Papers on the Jilin meteor showers: Science Press, Beijing, pp. 1-312 (in Chinese).
Li Chunlai, and Ouyang Ziyuan et al.,1992, Discovery of microtektites and microspherules in loess and its significance: Scientia Sinica (Series B), v. 23, no. 11, pp. 1210-1219 (in Chinese).

Lin Wenzhu, and Ouyang Ziyuan, 1991, Glasses after nuclear explosion and from impact craters and source rocks of tektite: Scientia Geologica Sinica, v. 34, no. 2, pp. 148-158 (in Chinese).

Lin Wenzhu, and Liu Gaokui, 1993, Infrared spectroscopic study on shock glasses and glassy rocks: Chinese Science Bulletin, v. 38, no. 3, pp. 250-253 (in Chinese)

Ouyang Ziyuan, 1988, Cosmochemistry: Science Press, Beijing, pp. 1-370 (in Chinese).

Wang Daode, et al., 1993, Introduction to Chinese meteorites: Science Press, Beijing, pp. 1-358 (in Chinese).

Wenzhu Lin, a senior researcher with the Institute of Geochemistry, Chinese Academy of Sciences, graduated from the Beijing Institute of Geology (now the China University of Geosciences) in 1962. Since graduation he has been mainly engaged in comprehensive geological studies of underground nuclear tests and cosmochemistry. Recently his interest has become focused on shock wave experiments, glassy materials, cosmic dust etc.

Ziyuan Ouyang, is a senior researcher and Academician at the Institute of Geochemistry, Chinese Academy of Sciences. He is Vicechairman of the Chinese Committee under SCOPE, a member of standing committee of the Chinese committee under IGBP, and member of the Chinese committee under ICL. A leading geochemist in China, he graduated from the Beijing College of Geology (now the China University of Geosciences) in 1956 and obtained his Master's degree in 1959 from the Institute of Geology, Chinese Academy of Sciences. His main interests are in cosmochemistry, nuclear geochemistry, resources and environmental science.
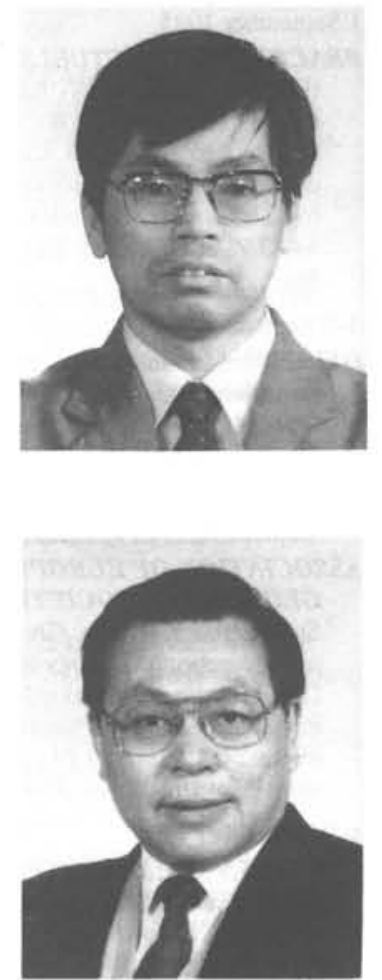